\title{
Erratum to: Surgical salvage of acquired lung lesions in extremely premature infants
}

\author{
Greg D. Sacks $\cdot$ Katherine Chung $\cdot$ Kevin Jamil • \\ Meena Garg • James C. Y. Dunn · Daniel A. DeUgarte
}

Published online: 5 March 2014

(c) Springer-Verlag Berlin Heidelberg 2014

\section{Erratum to: Pediatr Surg Int \\ DOI 10.1007/s00383-014-3482-1}

Unfortunately, part figures $3 \mathrm{~b}$ and $3 \mathrm{c}$ were incorrectly published in the original publication of this article.

The correct Fig. 3 is given below.
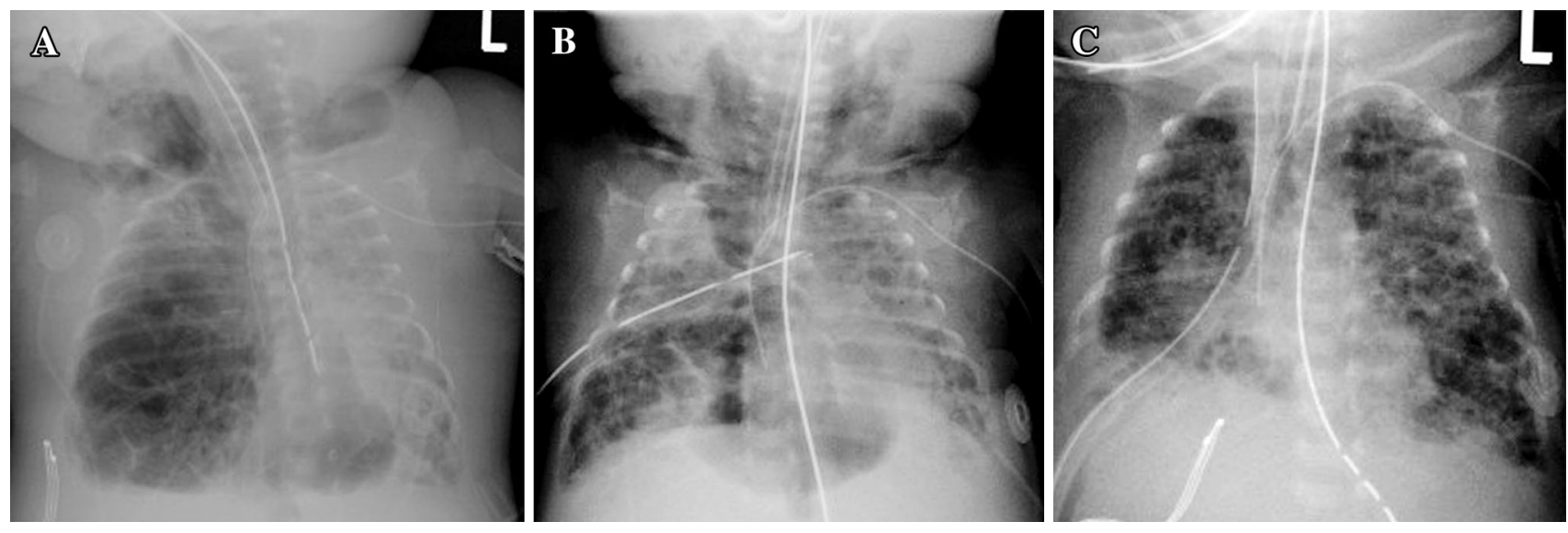

Fig. 3 A 23-week EGA infant developed diffuse cystic bronchopulmonary dysplasia with pneumomediastinum, midline shift and pulmonary interstitial emphysema (a). Tube thoracostomy reduced the midline shift but resulted in a persistent air leak (b). The patient underwent thoracotomy and was found to have a hyperinflated right middle lobe, which was successfully resected (c)

The online version of the original article can be found under doi:10.1007/s00383-014-3482-1.

G. D. Sacks · K. Jamil · J. C. Y. Dunn · D. A. DeUgarte $(\bowtie)$

Division of Pediatric Surgery, Department of Surgery, David Geffen School of Medicine at UCLA, 10833 Le Conte Avenue,

P. O. Box 709818, Los Angeles, CA 90095-7098, USA

e-mail: ddeugarte@mednet.ucla.edu

K. Chung · M. Garg

Division of Pediatric Neonatology, David Geffen

School of Medicine at UCLA, Los Angeles, USA 